\title{
Smilax aristolochiifolia Root Extract and Its Compounds Chlorogenic Acid and Astilbin Inhibit the Activity of $\alpha$-Amylase and $\alpha$-Glucosidase Enzymes
}

\author{
Viridiana Candelaria Pérez-Nájera, ${ }^{1}$ Janet Alejandra Gutiérrez-Uribe $\mathbb{D}{ }^{2}{ }^{2}$ \\ Marilena Antunes-Ricardo, ${ }^{2}$ Sergio Hidalgo-Figueroa, ${ }^{3}$ Carmen Lizette Del-Toro-Sánchez, ${ }^{4}$ \\ Luis A. Salazar-Olivo $\mathbb{i D},{ }^{5}$ and Eugenia Lugo-Cervantes $\mathbb{D}^{6}$ \\ ${ }^{1}$ División de Desarrollo Biotecnológico, Centro Universitario de la Ciénega-Universidad de Guadalajara, 47820 Ocotlán, Mexico \\ ${ }^{2}$ Tecnológico de Monterrey, Centro de Biotecnología-FEMSA, 64849 Monterrey, Mexico \\ ${ }^{3}$ Cátedra CONACYT, IPICYT/Consorcio de Investigación, Innovación y Desarrollo para las Zonas Áridas, \\ 78216 San Luis Potosí, Mexico \\ ${ }^{4}$ Departamento de Investigación y Posgrado en Alimentos, Universidad de Sonora, 83000 Hermosillo, Mexico \\ ${ }^{5}$ División de Biología Molecular, Instituto Potosino de Investigación Científica y Tecnológica (IPICYT), 78216 San Luis Potosí, Mexico \\ ${ }^{6}$ Unidad de Tecnología Alimentaria, Centro de Investigación y Asistencia en Tecnología y Diseño del Estado de Jalisco, \\ 44270 Guadalajara, Mexico
}

Correspondence should be addressed to Luis A. Salazar-Olivo; olivo@ipicyt.edu.mx and Eugenia Lugo-Cervantes; elugo@ciatej.mx

Received 20 February 2018; Revised 12 April 2018; Accepted 23 April 2018; Published 25 June 2018

Academic Editor: Michał Tomczyk

Copyright (C) 2018 Viridiana Candelaria Pérez-Nájera et al. This is an open access article distributed under the Creative Commons Attribution License, which permits unrestricted use, distribution, and reproduction in any medium, provided the original work is properly cited.

\begin{abstract}
Regulating activities of $\alpha$-amylase and $\alpha$-glucosidase through the use of specific inhibitors is a main strategy for controlling type 2 diabetes. Smilax aristolochiifolia root decoctions are traditionally used in Mexico as hypoglycemic and for weight loss, but the active principles and mechanisms underlying such putative metabolic effects are yet unknown. Here, we isolated the major bioactive compounds from a hydroethanolic extract of $S$. aristolochiifolia root by fast centrifugal partition chromatography and evaluated their effects against pancreatic $\alpha$-amylase and yeast $\alpha$-glucosidase. A chlorogenic acid-rich fraction (CAF) inhibited $\alpha$-amylase activity with an $\mathrm{IC}_{50}$ value of $59.28 \mu \mathrm{g} / \mathrm{mL}$ in an uncompetitive manner and $\alpha$-glucosidase activity with an $\mathrm{IC}_{50}$ value of $9.27 \mu \mathrm{g} / \mathrm{mL}$ in a noncompetitive mode. Also, an astilbin-rich fraction (ABF) inhibited $\alpha$-glucosidase activity with an $\mathrm{IC}_{50} \mathrm{value}$ of $12.30 \mu \mathrm{g} / \mathrm{mL}$, in a noncompetitive manner. CAF inhibition $\alpha$-amylase was as active as acarbose while both CAF and ABF were 50 -fold more potent inhibitors of $\alpha$-glucosidase than acarbose. The molecular docking results of chlorogenic acid and astilbin with $\alpha$-amylase and $\alpha$-glucosidase enzymes correlated with the inhibition mechanisms suggested by enzymatic assays. Our results prove that $S$. aristolochiifolia roots contain chlorogenic acid and astilbin, which inhibit carbohydrates-hydrolyzing enzymes, suggesting a new mechanism for the hypoglycemic effect reported for this plant.
\end{abstract}

\section{Introduction}

Diabetes mellitus is one of the most common chronic diseases in nearly all countries and continues to increase in number and significance, as economic development and urbanization lead to lifestyles characterized by reduced physical activity and increased obesity [1]. Diabetes mellitus is characterized by abnormally high plasma glucose concentration, resulting from insufficient or inefficient insulin secretion, with alterations in carbohydrate, protein, and lipid metabolism. Hyperglycemia has played a central role in the pathogenesis of complications related to diabetes mellitus, such as retinopathy, cataract, atherosclerosis, neuropathy, nephropathy, and impaired wound healing [2]. One therapeutic approach 
for decreasing postprandial hyperglycemia is to reduce the intestinal absorption of glucose from food, through inhibiting the intestinal carbohydrate-hydrolyzing enzymes, $\alpha$ amylase and $\alpha$-glucosidase. Synthetic drugs such as acarbose, voglibose, and miglitol are widely used as inhibitors of these enzymes in the management of patients with type 2 diabetes $[3,4]$. However, these inhibitors are reported to cause several side effects, such as abdominal distension, flatulence, meteorism, and diarrhea. Previously studies suggested that the consumption of dietary polyphenols might reduce the risk of type 2 diabetes and its complications [5-8]. Therefore, efforts have been directed toward finding natural and safer $\alpha$-amylase and $\alpha$-glucosidase inhibitors, and the search of such agents in traditional medicinal plants has become more important [9].

Smilax aristolochiifolia Miller (Smilacaceae), popularly known as zarzaparrilla, is widely distributed in Mexico [10] and commonly employed as root decoctions indicated as hypoglycemic [11] and for weight loss [12]. Pharmacological research has reported hematopoietic [13], hypoglycemic, and hypotensive effects [14] for the root of S. aristolochiifolia. Although antidiabetic potential has also been reported for other Smilax species, mainly of S. china $[15,16]$, the identity of bioactive compounds responsible for the antidiabetic effects of S. aristolochiifolia as well as their mechanisms of action are yet unknown. Therefore, we aim to identify the major bioactive compounds from $S$. aristolochiifolia root and to characterize their effects on $\alpha$-amylase and $\alpha$-glucosidase enzymatic activities.

\section{Materials and Methods}

2.1. Materials. Plants of Smilax aristolochiifolia Miller (including the roots) were collected in Apazapan, Veracruz, Mexico $\left(19^{\circ} 19^{\prime} 25.6^{\prime \prime} \mathrm{N}\right.$ and $\left.96^{\circ} 43^{\prime} 17.3^{\prime \prime} \mathrm{W}\right)$ in October 2015. Plant material was authenticated by Dr. M. Chazaro (Biology Department, Universidad Veracruzana), and a voucher specimen (10855) was deposited in the Institute of Ecology herbarium (IE-XAL), Xalapa, Veracruz, Mexico. $\alpha$-Glucosidase (EC 3.2.1.20, from Saccharomyces cerevisiae, $28 \mathrm{U} / \mathrm{mg}$ ), acarbose, $\rho$-nitrophenyl- $\alpha$-D-glucopyranoside (pNPG), porcine pancreatic $\alpha$-amylase (EC 3.2.1.1, type VI-B, from porcine pancreas, $\geq 10 \mathrm{U} / \mathrm{mg}$ ), and 3,5-dinitrosalicylic acid reagent (DNS) were purchased from Sigma-Aldrich Co. (St. Louis, MO, USA). The soluble starch was purchased from Jalmek Científica (Monterrey, NL, Mexico).

2.2. Preparation of S. aristolochiifolia Root Extract. The root of the plant was dried in the dark at room temperature and the dried material was then milled with a ball mill. Preliminary assays showed that extraction of S. aristolochiifolia roots by aqueous infusion or hydroethanolic maceration gives rise to the same profile of elution (Figure S1), although maceration produced a 2 -fold higher yield than infusion $(15.28 \%$ by infusion and $30.11 \%$ by maceration). The extraction was performed by maceration at room temperature $\left(25^{\circ} \mathrm{C}\right)$ and stirring overnight using a solid: liquid ratio of $1: 20 \mathrm{w} / \mathrm{v}$ in ethanol: water $(1: 1, \mathrm{v} / \mathrm{v})$ as solvent. The $S$. aristolochiifolia root extract (SAR) was obtained by filtration across Whatman paper no. 4. Then, ethanol was eliminated by concentration under vacuum (IKA RV 10 digital, Staufen, Germany) at $40^{\circ} \mathrm{C}$ and water by freeze-drying. Dry SAR was stored at $-80^{\circ} \mathrm{C}$ until use.

\subsection{Fast Centrifugal Partition Chromatography. Fractions} from SAR were obtained in a preparative fast centrifugal partition chromatography (FCPC) instrument (Kromaton, Angers, France), with rotor capacity of $1 \mathrm{~L}$, operated in dualmode: $0-57 \mathrm{~min}$ in descending mode, and $58-120 \mathrm{~min}$ in ascending mode at $1000 \mathrm{rpm}$ and a flow rate of $10 \mathrm{~mL} / \mathrm{min}$ using ethyl acetate: water $(1: 1 \mathrm{v} / \mathrm{v})$ as the two-phase solvent system, according to preliminary assays (Table S1). SAR ( $10 \mathrm{~g}$ ) was dissolved in $160 \mathrm{~mL}$ of solvent system, filtered, and pumped into the rotor. One hundred and twenty fractions were collected and grouped in pools of 10 fractions according to similarity of their partition coefficient $\left(k_{d}\right)$ values to facilitate their analysis. A total 12 pools were concentrated to dryness at $45^{\circ} \mathrm{C}$ under reduced pressure (EZ-2 Plus, Genevac Ltd., UK) and stored at $-20^{\circ} \mathrm{C}$ until testing.

2.4. High Performance Liquid Chromatography Analysis. SAR and its FCPC-obtained fractions were analyzed by HPLCDAD (Agilent Technologies, 1200 Series, Santa Clara, CA) according to the method described by Becerra-Moreno et al. [17] with some modifications. The compounds were separated in a Luna $5 \mathrm{U} \mathrm{C}_{18}, 4.6 \mathrm{~mm} \mathrm{ID} \times 250 \mathrm{~mm}(5 \mu \mathrm{m})$ column (Phenomex, Torrance, CA). The mobile phase was constituted by solvent A, HPLC grade water (BDH, Poole, UK) acidified with $0.1 \%$ formic acid (CTR Scientific, Monterrey, NL, Mexico), and solvent B, HPLC grade methanol (BDH, Poole, UK), using a gradient at a flow rate of $0.8 \mathrm{~mL} / \mathrm{min}$. The proportion of the mobile phase was maintained as follows: $0-3 \mathrm{~min}(\mathrm{~B}$, $0 \%$ to $18 \%$ ); $3-8 \mathrm{~min}(\mathrm{~B}, 18 \%$ to $30 \%) ; 8-35 \mathrm{~min}$ (B, $30 \%$ to $42 \%$ ); $35-40 \min (\mathrm{B}, 42 \%$ to $48 \%) ; 40-45 \min$ (B, $48 \%$ to $60 \%$ ); $45-50 \mathrm{~min}$ (B, $60 \%$ to $100 \%$ ); $50-60 \mathrm{~min}$ (B, $100 \%$ to $0 \%)$. Chromatograms were obtained at $280 \mathrm{~nm}, 10 \mu \mathrm{L}$ of sample was injected, and UV absorption spectra were collected. The results of quantification were expressed as chlorogenic acid or kaempferol-3-O-glucoside equivalents, based on the calibration curve of the corresponding standards.

Identification of major compounds was carried out by liquid chromatography coupled with time-of-flight mass spectrometry (LC/MS-TOF) (1100 Series, Agilent Technologies, Santa Clara, CA), using the same chromatographic conditions described above. Ionization was carried out using an electrospray ionization source in positive mode $\left(\mathrm{ESI}^{+}\right)$ with the following conditions: range for mass scan covered from $\mathrm{m} / z 140$ to 1000 , nitrogen gas temperature set at $350^{\circ} \mathrm{C}$, gas flow rate at $11 \mathrm{~L} / \mathrm{min}$, nebulizer pressure at $50 \mathrm{psi}, 3500 \mathrm{~V}$ capillary voltage, and $50 \mathrm{~V}$ in fragmentor. Extracted ion chromatograms were obtained by considering the exact mass of the compound using Analyst QS 1.1 software (Applied Biosystems, Carlsbad, CA).

\subsection{Enzyme Inhibition Assays and Action Mechanism Study}

2.5.1. Assay of $\alpha$-Amylase Activity. The $\alpha$-amylase inhibitory activity of SAR, CAF, and ABF was determined by measuring 
the reducing power of released oligosaccharide from soluble starch according to the method of Miller [18]. A series of tests at varying concentrations of both substrate and inhibitor were conducted to determine inhibition types. SAR, CAF, and $\mathrm{ABF}$ were prepared at concentrations of 1 to $200 \mu \mathrm{g} / \mathrm{mL}$ in $20 \mathrm{mM}$ phosphate buffer with $6.2 \mathrm{mM}$ sodium chloride at $\mathrm{pH}$ 6.9. Porcine pancreatic $\alpha$-amylase at $5 \mathrm{U} / \mathrm{mL}$ and $1 \%$ soluble starch solutions were prepared in the same buffer. All solutions were prepared immediately prior to each test.

Aliquots of an $\alpha$-amylase solution of $500 \mu \mathrm{L}$ and a sample solution of $500 \mu \mathrm{L}$ were mixed in a $15 \mathrm{~mL}$ Eppendorf tube and incubated at $20^{\circ} \mathrm{C}$ for $10 \mathrm{~min}$. The reaction was initiated by adding $1 \mathrm{~mL}$ of starch solution into the mixture and incubated during $10 \mathrm{~min}$ at $20^{\circ} \mathrm{C}$. Afterwards, $1 \mathrm{~mL}$ of 3,5-dinitrosalicylic acid (DNS) reagent solution was added followed by heating in boiling water for $15 \mathrm{~min}$ to develop color. The reaction was stopped by cooling down in ice water. The reaction mixture was diluted with $9 \mathrm{~mL}$ of distilled water and the absorbance was read at $540 \mathrm{~nm}$ using a spectrophotometer (UV-VIS 6405, JENWAY, UK). Acarbose was used as a positive control and phosphate buffer as a negative control. The inhibition percentage was calculated following the equation:

$$
\% \text { Inhibition }=\frac{\mathrm{Abs}_{\text {negative control }}-\mathrm{Abs}_{\text {sample }}}{\mathrm{Abs}_{\text {negative control }}} \times 100
$$

2.5.2. Assay of $\alpha$-Glucosidase Activity. The $\alpha$-glucosidase inhibitory activity of SAR, CAF, and ABF was assayed by the pNPG ( $\rho$-nitrophenyl- $\alpha$-D-glucopyranoside) method [19]. Briefly, reaction mixtures consisting of $25 \mu \mathrm{L}$ of $\alpha$-glucosidase from S. cerevisiae $(0.2 \mathrm{U} / \mathrm{mL})$ (Sigma-Aldrich, G5003) and $25 \mu \mathrm{L}$ of different concentrations ( 1 to $200 \mu \mathrm{g} / \mathrm{mL}$ ) of sample solutions were preincubated in a 96 -well plate at $20^{\circ} \mathrm{C}$ for $10 \mathrm{~min}$. Afterwards, the reaction was started by adding $50 \mu \mathrm{L}$ of $2 \mathrm{mM}$ pNPG to each well. After $20 \mathrm{~min}$, the reaction was stopped by adding $50 \mu \mathrm{L}$ of $0.2 \mathrm{M} \mathrm{Na}_{2} \mathrm{CO}_{3}$. All solutions were prepared immediately prior to each test and $20 \mathrm{mM}$ phosphate buffer with $6.2 \mathrm{mM}$ sodium chloride at $\mathrm{pH} 6.9$ was used as vehicle. The $\rho$-nitrophenol product released from the pNPG substrate was used to quantify the enzymatic activity; the absorbance was measured at $405 \mathrm{~nm}$ in a microplate reader (Bio-Rad model 550, Berkeley, CA). The percentage of inhibition was calculated according to (1).

2.5.3. Determination of Enzymatic Inhibitory Model by Kinetics Analysis. The type of enzyme inhibition was graphically determined using the Lineweaver-Burk plot. The inhibition activity $\left(\mathrm{IC}_{50}\right)$ was used to evaluate the effectiveness of an inhibitor. $\mathrm{IC}_{50}$ value is defined as the concentration of a test substance required achieving half maximal inhibition of a given reaction. $\mathrm{IC}_{50}$ values were calculated using the nonlinear regression and logistic function.

2.6. Homology Modeling of $\alpha$-Glucosidase. Unlike $\alpha$-amylase, the crystallographic structure for $\alpha$-glucosidase enzyme is not available; therefore the 3D model of $\alpha$-glucosidase from Saccharomyces cerevisiae was generated based on the sequence similarity by using homology modeling. The amino acid sequence of the target protein was retrieved from NCBI (https://www.ncbi.nlm.nih.gov/) with ID: P53341.1. BLASTp server was used against Protein Data Bank database to find the appropriate structure template for the homology model. The alignment between the sequences was performed using the MODELLER v.9.18 program. One hundred models were built and the single model was selected by DOPE (Discrete Optimized Protein Energy) score. The final model was validated using two tools ProSa (Protein Structure Analysis) and QMEAN (Qualitative Model Energy Analysis).

2.7. Molecular Docking Studies. Molecular docking studies were used to explore the binding mode between ligand and receptor [20]. According to results of enzymatic assays and inhibition type, we investigated the binding modes of chlorogenic acid and astilbin against $\alpha$-amylase and $\alpha$ glucosidase enzymes. First, the three-dimensional structure of porcine pancreatic $\alpha$-amylase with malto-oligosaccharides (PDB ID: 1UA3) was obtained from the Protein Data Bank (PDB) database. For calculation, the malto-oligosaccharides were conserved and all water molecules were removed from the crystallographic structure. The molecular docking was performed using AutoDock 4.2 and AutoDock Tools (ADT, v.1.5.6). The grid dimensions were adjusted to $60 \times 60 \times$ 60 points separated by $0.375 \AA$. PyMOL (PyMOL Molecular Graphics System, San Carlos, CA, USA) and Discovery Studio Visualizer v.17.2.0.16349 (BIOVIA, San Diego, CA, USA) were used for visualization.

On the other hand, the 3D structures of chlorogenic acid and astilbin were obtained from PubChem in the NCBI database. The dimensions of the grid, which represents the coordinates of the parameters in which the ligand can be moved, were $30 \times 40 \times 40$ points separated by $1.0 \AA$. To establish the grid, it was chosen based on the binding sites reported in noncompetitive inhibition for $\alpha$-glucosidase, covering the residues ASP214, GLU276 and ASP349, ILE149, PRO150 and ASP232, and SER311, PRO312, VAL319, THR310, GLY309, VAL308, ASP307, PHE321 and PRO320 [21-23]. In the default parameters, the Lamarckian genetic algorithm (LGA) was chosen for docking calculations, and 100 experiments per ligand were performed. Compared with the rigidity of the protein, the ligand remained flexible. In the results of molecular docking, the pose with lowest docking energy and maximum number of conformations was selected to represent its most favorable binding mode predicted by this program.

2.8. Statistical Analysis. The enzymatic assays were performed in triplicate. The results were analyzed using Statgraphics Centurion XVII v.17.2.00 with Tukey's HSD test. For each data set, $P<0.05$ was considered statistically significant. The experimental results were expressed as the mean \pm standard deviation of at least two separate experiments.

\section{Results and Discussion}

3.1. Analysis of S. aristolochiifolia Root Extract and Isolation of Chlorogenic Acid and Astilbin by Fast Centrifugal Partition Chromatography (FCPC). Chromatographic analyses of SAR at $280 \mathrm{~nm}$ (Figure 1) showed two main phenolic constituents, peak 2 eluting at $18.59 \mathrm{~min}$ and peak 4 eluting 


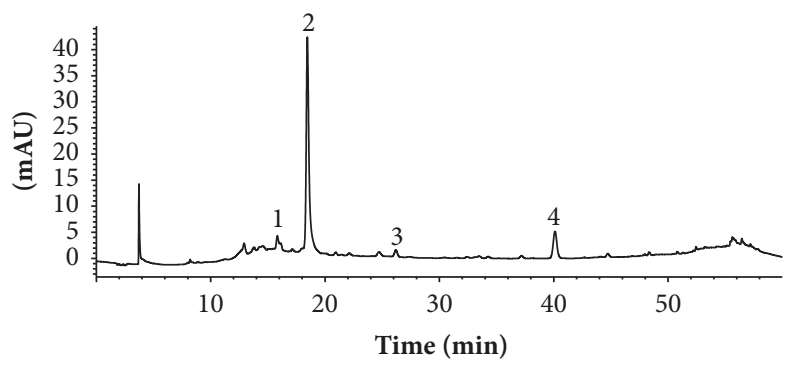

FIGURE 1: HPLC-UV/Vis chromatogram shown at $280 \mathrm{~nm}$ of S. aristolochiifolia root hydroethanolic extract. Conditions: reverse-phase C18 column $(4.6 \times 150 \mathrm{~mm}, 5 \mu \mathrm{m}$, Phenomex); mobile phase, water acidified with $0.1 \%$ formic acid and methanol using a concentration gradient (see methodology); flow rate: $0.8 \mathrm{~mL} / \mathrm{min}$.

at $40.37 \mathrm{~min}$. Two minor SAR constituents, peaks 1 and 3, were not considered in the present work. Peaks 2 and 4 were tentatively identified according to their UV absorption, $m / z$, fragmentation patterns, and previously reported data. The UV-vis spectrum of peak 2 showed characteristic bands of a caffeine residue with $\lambda_{\max }$ of 240 and $327 \mathrm{~nm}$ (Figure 2(b)) and a molecular ion of $355.09 \mathrm{~m} / z\left[\mathrm{M}+\mathrm{H}^{+}\right]$(Figure 2(a)) corresponding to the chlorogenic acid (Figure 2(c)). The identity of chlorogenic acid was corroborated by standard retention time (data not showed). The UV-vis spectrum of peak 4 had an absorption maximum of $290 \mathrm{~nm}$ (Figure 2(e)) and a molecular ion of $451.12 \mathrm{~m} / z\left[\mathrm{M}+\mathrm{H}^{+}\right]$(Figure 2(d)), which is characteristic of astilbin, a flavonoid compound (Figure 2(f)) [24]. Our results constitute the first report of the presence of chlorogenic acid and astilbin in S. aristolochiifolia, though both compounds have been previously reported for other species in the genus Smilax [25-30].

Chlorogenic acid is a phenolic compound with important pharmacological properties, such as neuroprotective [31], antihyperlipidemic [32], hypoglycemic [33, 34], insulin secretagogue, and sensitizer [35-37]. Chlorogenic acid is present in many plant species and appreciable chlorogenic acid contents have been shown in Cecropia obtusifolia, Vaccinium corymbosum, Ilex paraguariensis, Camellia sinensis, and green coffee beans $[34,38-40]$. In this study, $83.19 \mathrm{mg}$ chlorogenic acid equivalents per gram of SAR (2504 mg/100 g dry matter) were obtained (Table 1). This concentration of chlorogenic acid is higher than those reported for other sources such as I. paraguariensis (1599.6 mg/100 g dry matter) [38], Cecropia obtusifolia (1330 mg/100 g dry matter) [34], and coffee pulp (309.7 mg/100 g dry matter) [41] and makes S. aristolochiifolia an advantageous source of chlorogenic acid. On the other hand, $3.72 \mathrm{mg}$ of astilbin expressed as kaempferol3-O-glucoside equivalents was obtained per gram of SAR (112 $\mathrm{mg} / 100 \mathrm{~g}$ dry matter) below other species as Smilax glabra $(1 \%-4 \%, w / w)$ [42] or Engelhardia roxburghiana [43] (Table 1).

When SAR was subjected to one-step FCPC separation, chlorogenic acid was recovered mainly in fractions around of $0.22 k_{d}$ (Figure $3(\mathrm{a})$ ), while astilbin appeared mainly in fractions with a $k_{d}$ value of 2.68 (Figure $3(\mathrm{~b})$ ). It was possible to recover both compounds in one-step FCPC separation because we used the dual-mode in which switching the phases extrudes the contents of the column, retrieving compounds of high $k_{d}$ values as peak 4 . The pool of chlorogenic acid-enriched fractions (CAF) achieved concentrations of this compound up to 1.02-fold more than SAR and the pool of astilbin-enriched fractions (ABF) reached 13.11-fold more astilbin than extract (Table 1). CAF and ABF were selected for the next assays.

3.2. Effects of S. aristolochiifolia Root Extract (SAR), Chlorogenic Acid Fraction (CAF), and Astilbin Fraction (ABF) on $\alpha$ Amylase and $\alpha$-Glucosidase Activities. SAR, CAF, and ABF blocked the pancreatic $\alpha$-amylase activity in a concentrationresponsive manner. SAR $50 \mu \mathrm{g} / \mathrm{mL}$ inhibited $\alpha$-amylase activity by $22 \%$ while SAR $100 \mu \mathrm{g} / \mathrm{mL}$ inhibited $\alpha$-amylase by $56 \%$ and SAR $200 \mu \mathrm{g} / \mathrm{mL}$ reached an enzymatic inhibition of $82 \%$, a similar inhibition level as the corresponding acarbose concentration. On the other hand, CAF $50 \mu \mathrm{g} / \mathrm{mL}$ inhibited $\alpha$-amylase activity by $40 \%$, while CAF $100 \mu \mathrm{g} / \mathrm{mL}$ inhibited the enzyme by $75 \%$, similar to acarbose. On the contrary, ABF exerted only marginal inhibitory effects against $\alpha$-amylase at all the assayed concentrations (Figure $4(\mathrm{a})$ ). The $\mathrm{IC}_{50}$ values in our $\alpha$-amylase assays were $90.01 \pm 3.97 \mu \mathrm{g} / \mathrm{mL}$ for SAR and $59.28 \pm 1.30 \mu \mathrm{g} / \mathrm{mL}$ for CAF, this last one statistically similar to the acarbose $\left(\mathrm{IC}_{50}: 58.59 \pm 1.06 \mu \mathrm{g} / \mathrm{mL}\right)$. Our results confirm recent reports showing the inhibitory effects of chlorogenic acid on $\alpha$-amylase activity [44-46].

We also evaluated the effects of SAR and its fractions on yeast $\alpha$-glucosidase activity. SAR $10 \mu \mathrm{g} / \mathrm{mL}$ inhibited $\alpha$ glucosidase activity by $34 \%$ and SAR $20 \mu \mathrm{g} / \mathrm{mL}$ inhibited this enzyme by $81 \%$. In the same manner, CAF $10 \mu \mathrm{g} / \mathrm{mL}$ inhibited $\alpha$-glucosidase activity by $47 \%$ and CAF $20 \mu \mathrm{g} / \mathrm{mL}$ inhibited $\alpha$-glucosidase by $70 \%$, while ABF $10 \mu \mathrm{g} / \mathrm{mL}$ blocked $\alpha$-glucosidase in $35 \%$ and $\mathrm{ABF} 20 \mu \mathrm{g} / \mathrm{mL}$ inhibited the enzyme by $78 \%$. All three preparations at $50 \mu \mathrm{g} / \mathrm{mL}$ blocked $\alpha$-glucosidase activity by $98 \%$ (Figure $4(\mathrm{~b})$ ). The $\mathrm{IC}_{50}$ values in our $\alpha$-glucosidase assays were $12.39 \pm 0.33 \mu \mathrm{g} / \mathrm{mL}$ for SAR, $9.27 \pm 2.05 \mu \mathrm{g} / \mathrm{mL}$ for CAF, and $12.30 \pm 0.91 \mu \mathrm{g} / \mathrm{mL}$ for ABF. The inhibition of $\alpha$-glucosidase by $S$. china stem extract and chlorogenic acid has been previously reported but this is the first report on the inhibition of $\alpha$-glucosidase by astilbin. Moreover, the $\alpha$-glucosidase $\mathrm{IC}_{50}$ value of SAR was sensibly lower than $\mathrm{IC}_{50}$ value reported for $S$. china stem extract $\left(\mathrm{IC}_{50}: 51.7 \mu \mathrm{g} / \mathrm{mL}\right)$ [15], suggesting that $S$. aristolochiifolia 


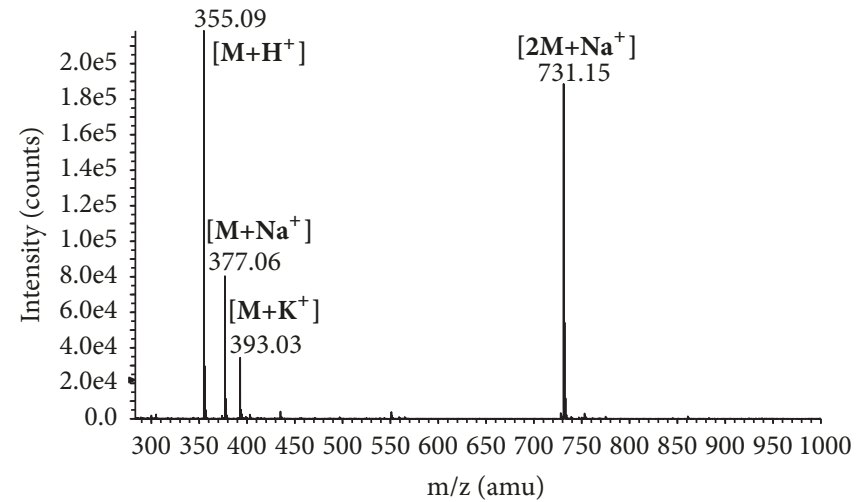

(a)<smiles>O=C(/C=C/c1ccc(O)c(O)c1)OC1CC(O)(C(=O)O)CC(O)C1O</smiles>

(c)

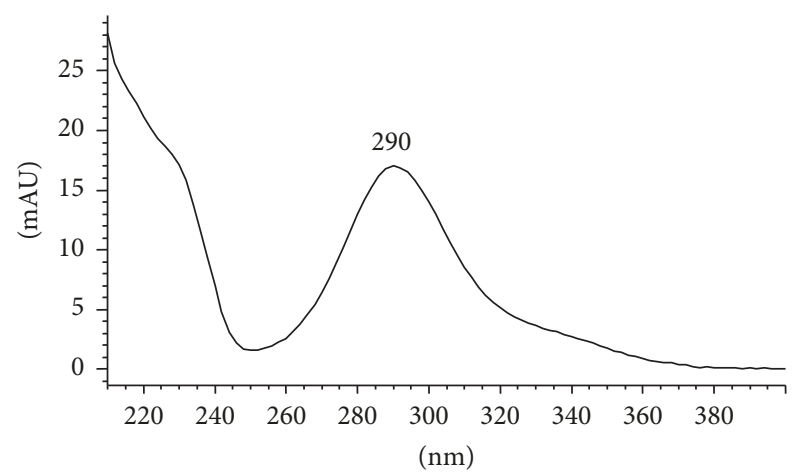

(e)

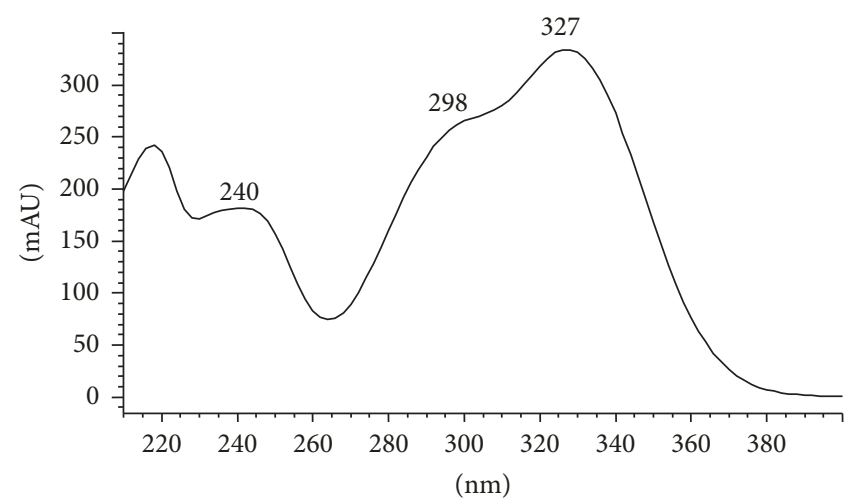

(b)

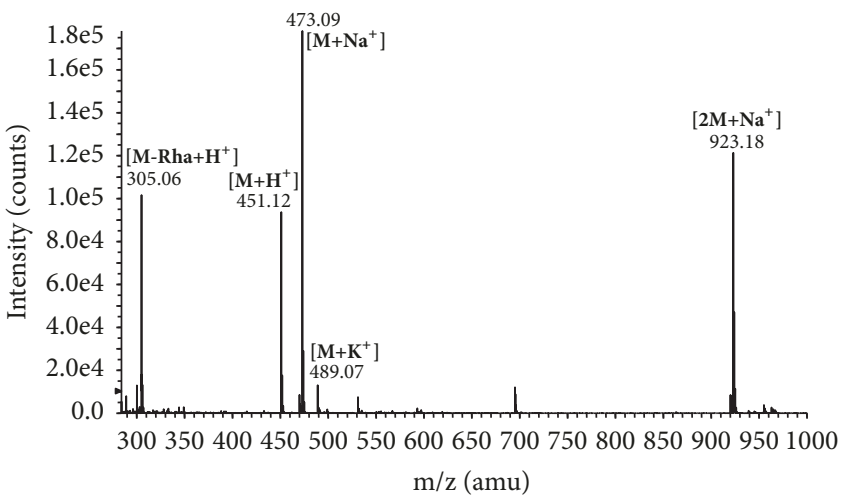

(d)<smiles>CC1OC(OC2C(=O)c3c(O)cc(O)cc3OC2c2ccc(O)c(O)c2)C(O)C(O)C1O</smiles>

(f)

FIGURE 2: Tentative identification of chlorogenic acid (c) and astilbin (f) by spectral analyses of mass spectrum by ESI/MS (a, d) and UV-vis $(\mathrm{b}, \mathrm{e})$.

TABLE 1: Chlorogenic acid and astilbin contents in SAR, CAF, and ABF.

\begin{tabular}{lccc}
\hline Sample & $k_{d}$ & Chlorogenic acid content (mg CAE/g) & Astilbin content (mg KGE/g) \\
\hline SAR & - & 83.19 & 3.72 \\
CAF & 0.22 & 84.77 & ND \\
ABF & 2.68 & ND & 48.76 \\
\hline
\end{tabular}

CAE, chlorogenic acid equivalents; KGE, kaempferol-3-O-glucoside equivalents; ND, not detected. S. aristolochiifolia root extract, SAR; chlorogenic acid-rich fraction, CAF; astilbin-rich fraction, ABF. 


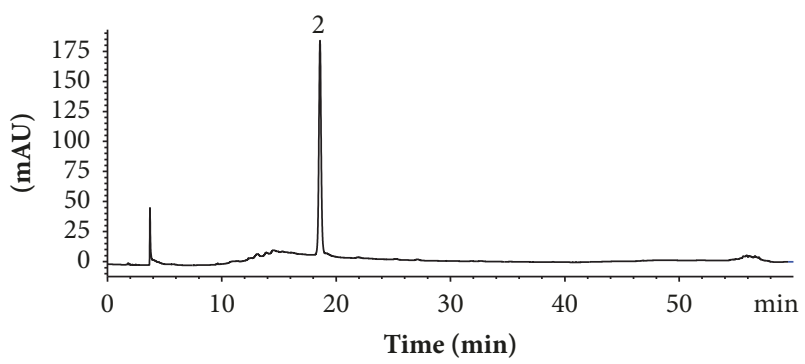

(a)

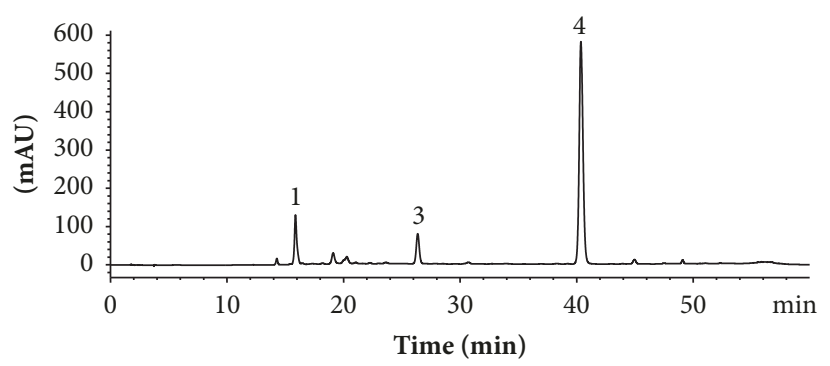

(b)

FIGURE 3: HPLC UV/Vis chromatograms of chlorogenic acid (CAF; a) and astilbin (ABF; b) rich fractions obtained by preparative FCPC from S. aristolochiifolia root extract. Conditions: two-phase solvent system, ethyl acetate: water (1:1 v/v); dual-mode: 0-57 min in descending mode and 58-120 min in ascending mode; flow rate, $10 \mathrm{~mL} / \mathrm{min}$; rotation speed, $1000 \mathrm{rpm}$; monitored at $280 \mathrm{~nm}$.

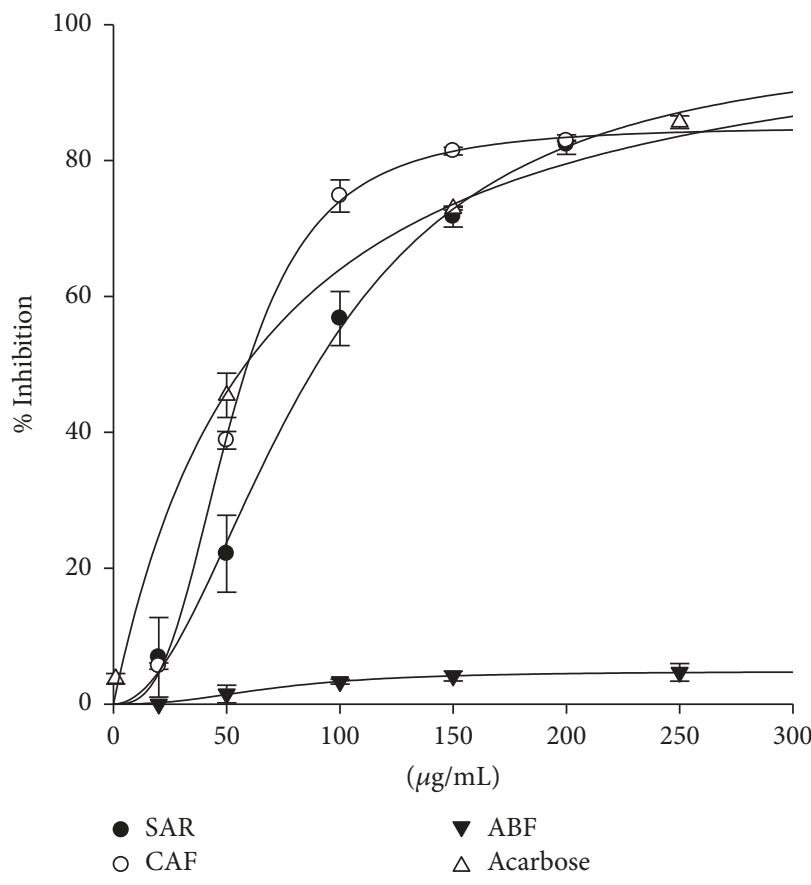

(a)

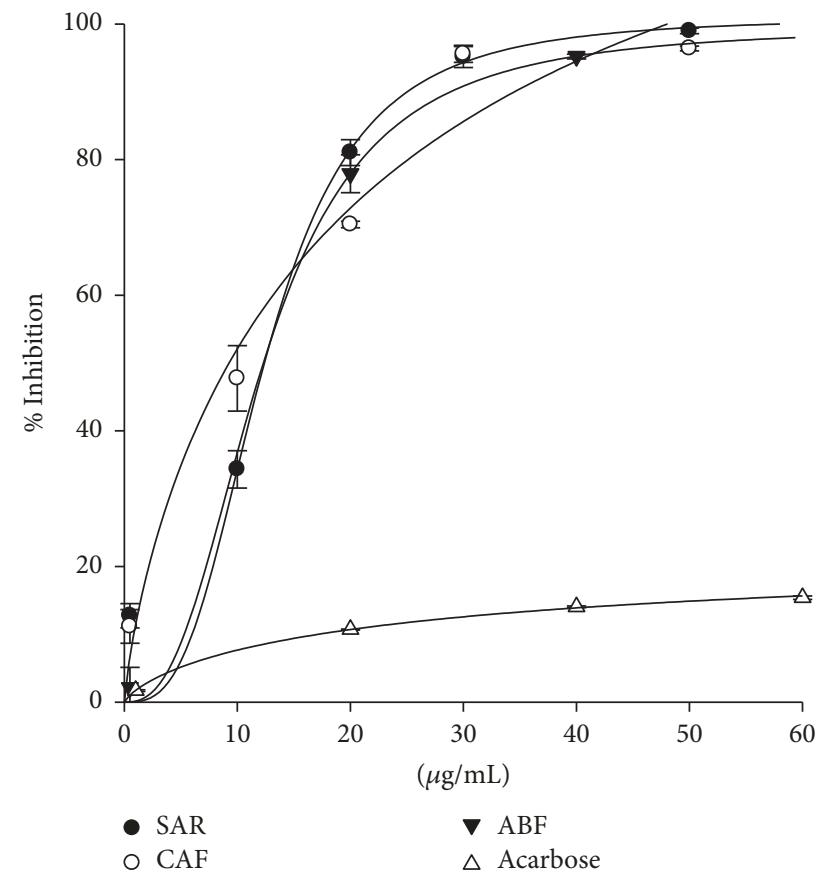

(b)

FIGURE 4: Inhibition of $\alpha$-amylase (a) and $\alpha$-glucosidase (b) enzymes by S. aristolochiifolia root (SAR) and its fractions rich in chlorogenic acid (CAF) and astilbin (ABF).

could be an optimal source for inhibitors of $\alpha$-glucosidase among Smilax species. CAF had the highest inhibitory activity compared with other preparations; these results are in accordance with a strong inhibition of chlorogenic acid against $\alpha$-glucosidase $[44,47]$. SAR and its FCPC-obtained fractions had up to 50 -fold more effective $\alpha$-glucosidase inhibitory activity compared with acarbose $\left(\mathrm{IC}_{50}: 673.29 \pm\right.$ $53.04 \mu \mathrm{g} / \mathrm{mL}$ ). Therefore, the inhibitory activity of $S$. aristolochiifolia root extract and its FCPC-obtained fractions against pancreatic $\alpha$-amylase and yeast $\alpha$-glucosidase may be one of the mechanisms of the hypoglycemic effect of $S$. aristolochiifolia [14]. However, further studies are required to extend this effect to mammalian systems.

3.3. Enzymatic Inhibitory Model. The double reciprocal Lineweaver-Burk plots revealed that the CAF inhibition of $\alpha$-amylase was uncompetitive since $k_{m}$ and $v_{\max }$ values were affected at the same degree by different CAF concentrations (Figure 5(a)). On the other hand, the inhibition of $\alpha$-glucosidase by SAR, CAF, and ABF preparations was noncompetitive since $k_{m}$ values for different concentrations of these preparations remained constant while their $v_{\max }$ values decreased with increased inhibitor concentration (Figures 5(b), 5(c), and 5(d)). Noncompetitive inhibition of $\alpha$ glucosidase has been reported for chlorogenic acid [48], apigenin [23], and xanthone derivatives [22].

\subsection{Three-Dimensional Structure of $\alpha$-Glucosidase Obtained} from Homology Modeling. Alignment analysis with Blastp showed that isomaltase from Saccharomyces cerevisiae has a high sequence identity (72\%) with the target; besides the active site is highly conserved (Figure 6). Therefore, the X-ray 


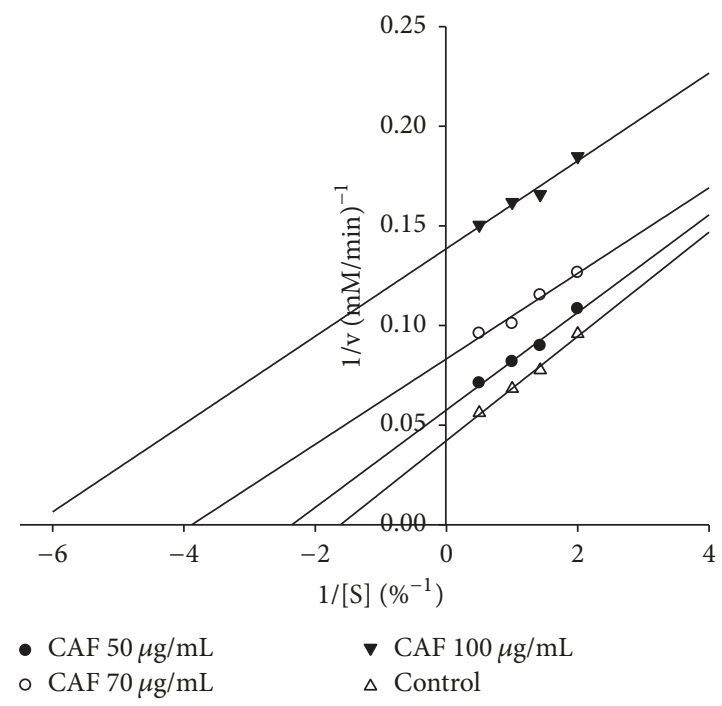

(a)

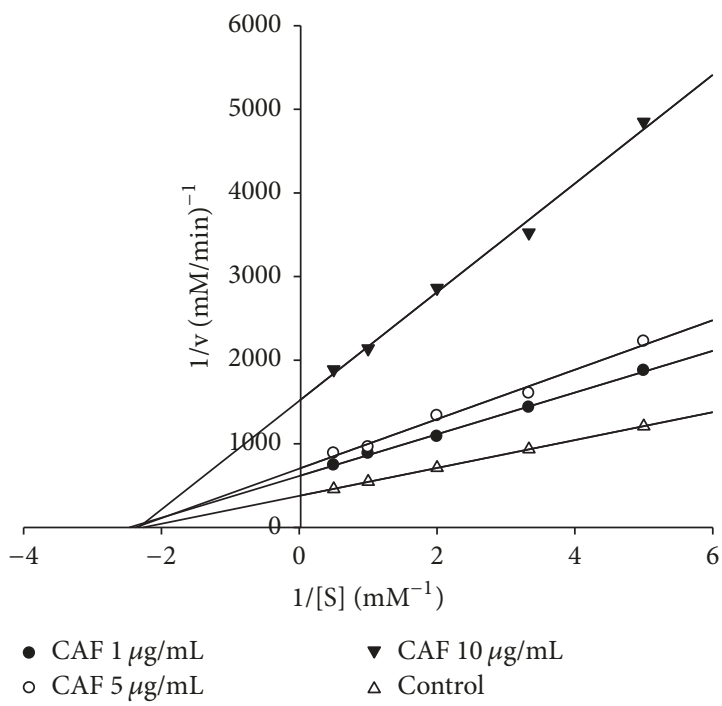

(c)

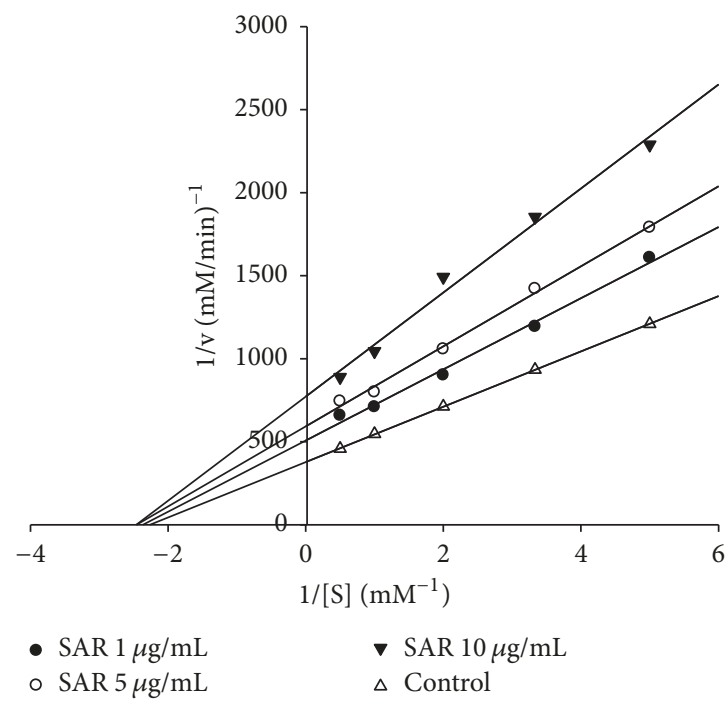

(b)

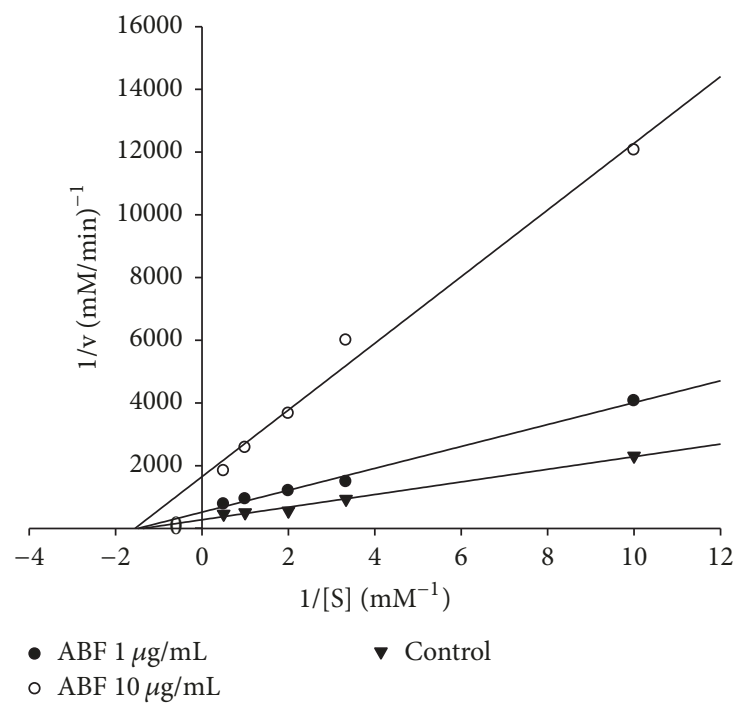

(d)

FIGURE 5: Lineweaver-Burk plots of $\alpha$-amylase (a) and $\alpha$-glucosidase (b, c, and d) activities by S. aristolochiifolia root extract (SAR), chlorogenic acid-rich fraction (CAF), and astilbin-rich fraction (ABF). The kinetics was assayed in the absence (control) and the presence of three different concentrations of each preparation.

crystal structure of isomaltase from $S$. cerevisiae (PDB ID: 3A47) was selected as template for homology modeling. According to the validation analysis, the theoretical model for $\alpha$-glucosidase was within the range of scores typically found for native proteins of similar size (Figure 7(a)). Furthermore, a QMEAN $Z$ score value of -1.22 for the predicted $\alpha$-glucosidase indicated it was of comparable quality to experimental structures (Figure 7(c)). On the other hand the energies in function of the position of the sequence of amino acids showed negative values, considering that positive values correspond to problematic or erroneous parts of the input structure (Figure $7(\mathrm{~b})$ ). Consequently, the predicted model for $\alpha$-glucosidase is a reliable model to performance molecular docking studies.
3.5. Molecular Docking Analysis on $\alpha$-Amylase and $\alpha$-Glucosidase. To get further insight into the binding mode between astilbin and chlorogenic acid with $\alpha$-glucosidase and chlorogenic acid with $\alpha$-amylase, the molecular docking was carried out. The docking analysis for chlorogenic acid with $\alpha$ amylase was done on the enzyme-substrate complex and the interactions were predicted close of active site, due to the fact that chlorogenic acid showed an uncompetitive inhibition. Unlike acarbose, which is a strong competitive inhibitor of $\alpha$ amylase, chlorogenic acid requires the formation of enzymesubstrate complex for binding. In the uncompetitive inhibition, the binding of substrate at the catalytic site may modify the $\alpha$-amylase structure, making the inhibitor binding site available. The better pose for chlorogenic acid obtained from 


\begin{tabular}{|c|c|}
\hline aln. & 40 \\
\hline 47 & S--SAHPETEPKWWKEATFYQIYPASFKDSNDDGWGDMKGIASKLEYIKELGADAIWISPFYD \\
\hline 53341.1 & MTISDHPETEPKWWKEATIYQIYPASFKDSNNDGWGDLKGITSKLQYIKDLGVDAIWVCPFYDSPQQD \\
\hline co & $* * * \quad * * * * * * * * * * * * \quad * * * * * \quad * * * \quad * * * \quad * * * \quad * * \quad * * * * \quad * * * * * * * \quad *$ \\
\hline _aln & 120 \\
\hline A47 & MGYDIANYEKVWPTYGTNEDCFALIEKTHKLGMKFITDLVINHCSSEHEWFKESRSSKTNPKRDWFFW \\
\hline 33 & MGYDISNYEKVWPTYGTNEDCFELIDKTHKLGMKFITDLVINHCSTEHEWFKESRSSKTNPKRDWFFW \\
\hline _cor & ***** $\quad * * * * * * * * * * * * * * * * \quad * * \quad * * * * * * * * * * * * * * * * * * * * \quad * * * * * * * * * * * * * * * * * * *$ \\
\hline _aln & 170 \\
\hline $\bar{A} 47$ & RPPKGYDAEGKPIPPNNWKSYFGGSAWTFDEKTQEFYLRLFCSTQPDLNWENEDCRKAIYESAVGYWL \\
\hline 533 & RPPKGYDAEGKPIPPNNWKSFFGGSAWTFDETTNEFYLRLFASRQVDLNWENEDCRRAIFESAVGFWL \\
\hline - $\mathrm{co}$ & $* * * * * * * * * * * * * * * * * * * * \quad * * * * * * * * * * \quad * \quad * * * * * * * \quad * * * * * * * * * * * * * \quad * * \quad * * * * * * *$ \\
\hline _aln & 240 \\
\hline 3A47 & DHGVDGFRIDVGSLYSKVVGLPDAPVVDKNSTWQSSDPYTLNGPRIHEFHQEMNQFIRNRVKDGREIM \\
\hline 533 & DHGVDGFRIDTAGLYSKRPGLPDSPIFDKTSKLQHPNWGSHNGPRIHEYHQELHRFMKNRVKDGREIM \\
\hline _co & $* * * * * * * \quad * * * \quad * \quad * * * * * * * * * *$ \\
\hline _aln & 300 \\
\hline 3447 & TVGEMQHASDETKRLYTSASRHELSELFNFSHTDVGTSPLFRYNLVPFELKDWKIALAELFRYINGTD \\
\hline 2533 & TVGEVAHGSD--NALYTSAARYEVSEVFSFTHVEVGTSPFFRYNIVPFTLKQWKEAIASNFLFINGTD \\
\hline _co & 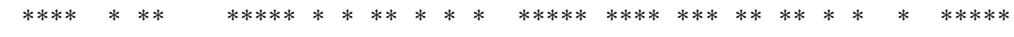 \\
\hline _aln. & 390 \\
\hline 3A47 & CWSTIYLENHDQPRSITRFGDDSPKNRVISGKLLSVLLSALTGTLYVYQGQELGQINFKNWPVEKYED \\
\hline P533 & SWATTYIENHDQARSITRFADDSPKYRKISGKLLTLLECSLTGTLYVYQGQEIGQINFKEWPIEKYED \\
\hline _CO & $* * * * * * * * \quad * * * * * * \quad * * * * * \quad * \quad * * * * * * \quad * \quad * * * * * * * * * * * * \quad * * * * * * \quad * * \quad * * * * *$ \\
\hline _aln & 440 \\
\hline $3 \bar{A} 47$ & VEIRNNYNAIKEEHGENSEEMKKFLEAIALISRDHARTPMQWSREEPNAGFSGPSAKPWFYLNDSFRE \\
\hline P533 & VDVKNNYEIIKKSFGKNSKEMKDFFKGIALLSRDHSRTPMPWTKDKPNAGFTGPDVKPWFLLNESFEQ \\
\hline - co & $\begin{array}{llllllllllllllll}* & * * * & * * & * & * * & * * * & * & * * * & * * * * & * * * * & * & * * * * * & * * & * * * * & * * & * *\end{array}$ \\
\hline _aln. & 500 \\
\hline 3A47 & GINVEDEIKDPNSVLNFWKEALKFRKAHKDITVYGYDFEFIDLDNKKLFSFTKKYNNKTLFAALNFSS \\
\hline P533 & GINVEQESRDDDSVLNFWKRALQARKKYKELMIYGYDFQFIDLDSDQIFSFTKEYEDKTLFAALNFSG \\
\hline _co & $* * * * * \quad * \quad * * * * * * * \quad * * \quad * * \quad *$ \\
\hline _aln. & 560 \\
\hline 3A47 & DATDFKIPN \\
\hline $\begin{array}{r}\text { P5334 } \\
\text { con }\end{array}$ & $\begin{array}{l}\text { EEIEFSLPREGASLSFILGNYD--DTDVSSRVLKPWEGRIYLVK } \\
\quad * * * * * * * * * * * * * * *\end{array}$ \\
\hline
\end{tabular}

Figure 6: Sequence alignment between $\alpha$-glucosidase (MAL12) (NCBI ID: P53341.1) and isomaltase (PDB ID: 3A47). * indicates conserved residues. The active site residues are indicated in bold blue types.

docking analysis showed lowest energy $(-5.97 \mathrm{Kcal} / \mathrm{mol})$, with highest binding affinity. The main interactions of chlorogenic acid with $\alpha$-amylase involved conventional hydrogen bonds with residues LYS200, GLU240, GLY306, and GLY308, in addition to a malto-oligosaccharide molecule (Figure 8(c)). Our results suggested an important correlation between the uncompetitive inhibition on $\alpha$-amylase (in vitro assay) and predicted molecular ligand-enzyme interactions. The hydroxyl groups of chlorogenic acid could be anchored near the active site of $\alpha$-amylase (Figure 8(a)).

On the other hand, for the analysis of molecular docking for $\alpha$-glucosidase, both compounds had different binding characteristics, as shown in their suggested binding modes (Figure 9). While the binding site for chlorogenic acid on $\alpha$-glucosidase was situated in a place away from the active site, astilbin was close to the active site of the enzyme; both poses corresponded with noncompetitive inhibition mode (Figure 9(c)). The complex of $\alpha$-glucosidase-chlorogenic acid showed lowest binding energy of $-3.75 \mathrm{kcal} / \mathrm{mol}$. Chlorogenic acid formed hydrogen bonds with the residues SER161, PHE165, and LYS418, and a $\pi-\pi$ T-shaped interaction between A ring and PHE172 was found (Figure 9(d)). It is likely that this binding interaction of chlorogenic acid to the allosteric site of $\alpha$-glucosidase would probably perturb the protein structure and subsequently the enzyme activity. A similar result was obtained with xanthone derivatives, as noncompetitive inhibitors of $\alpha$-glucosidase with interactions of hydrogen bonding and $\pi-\pi$ stacking [21].

The $\alpha$-glucosidase-astilbin inhibitor complex showed lowest binding energy of $-4.56 \mathrm{kcal} / \mathrm{mol}$ compared with other poses. Astilbin formed hydrogen-bonding interactions with residues GLU304, PRO309, ASN241, and ASN246, and a $\pi$ cation interaction between B ring with HIS279 was found (Figure 9(e)). The hydrogen bonds played a role in the binding of astilbin to $\alpha$-glucosidase; two hydrogen bonds were formed between the oxygen of the hydroxyl groups at the $\mathrm{C}-3^{\prime}$ and $\mathrm{C}-4^{\prime}$ position on the $\mathrm{B}$ ring of astilbin and GLU304. Although the glycosylation of flavonoids decreased 


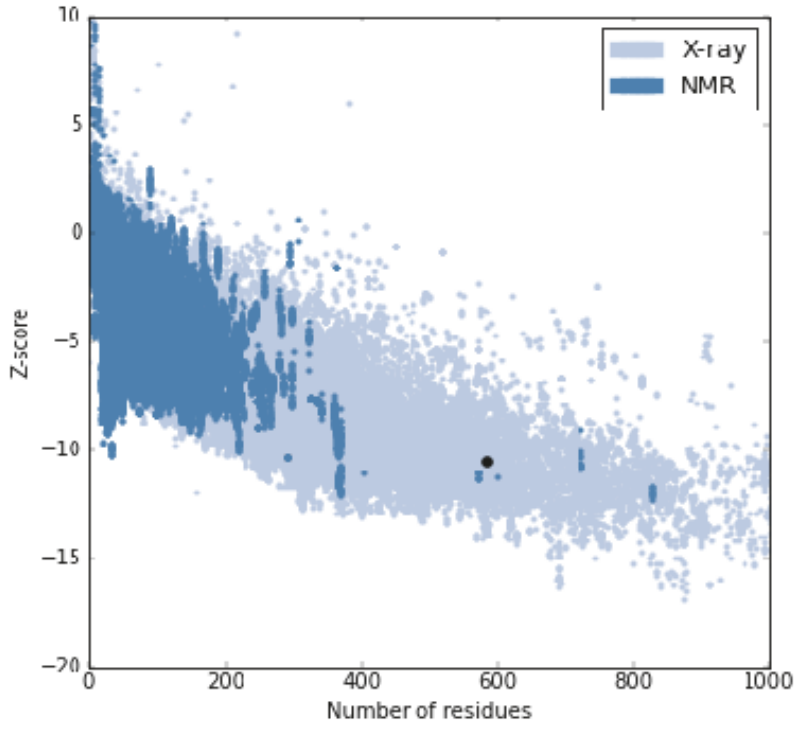

(a)

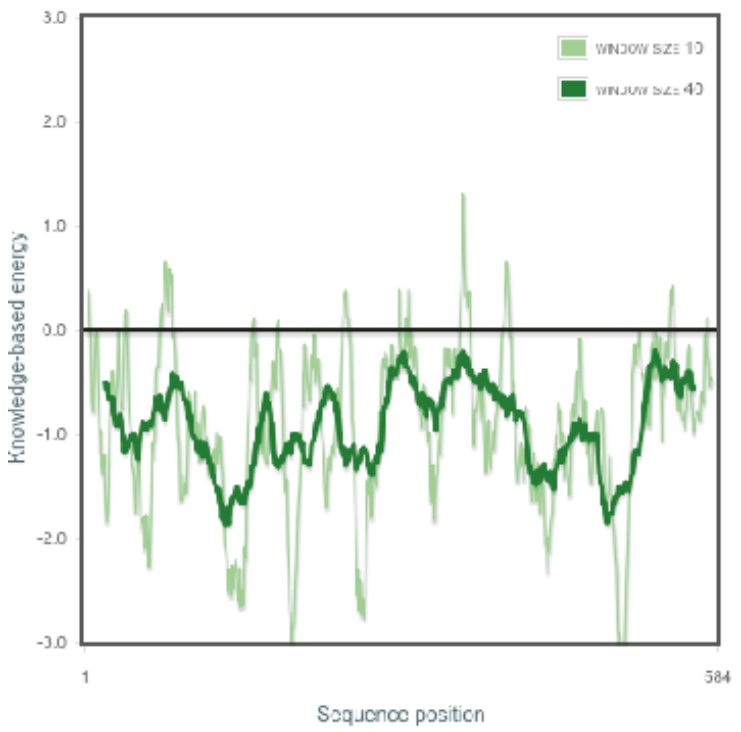

(b)

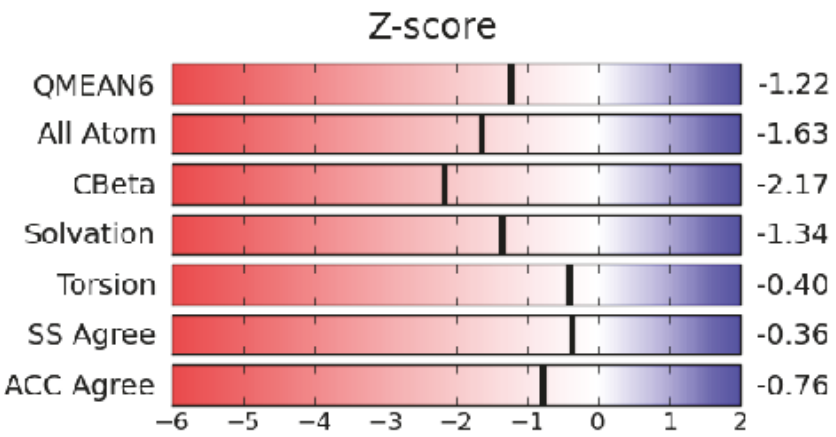

(c)

Figure 7: Model evaluation in function of QMEAN Z-score $(a, c)$ and comparison of the ProSa energy profiles for the homology modeled structure of $\alpha$-glucosidase (light green) and the X-ray structure of isomaltase (green) (b).

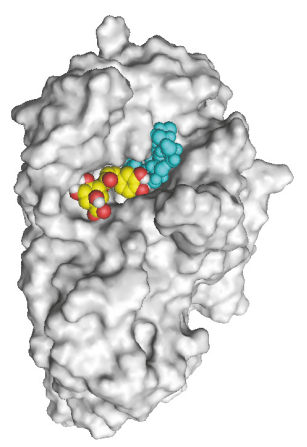

(a)

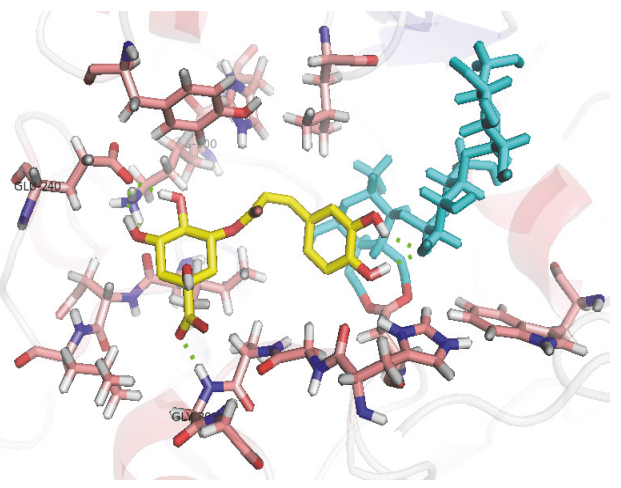

(b)

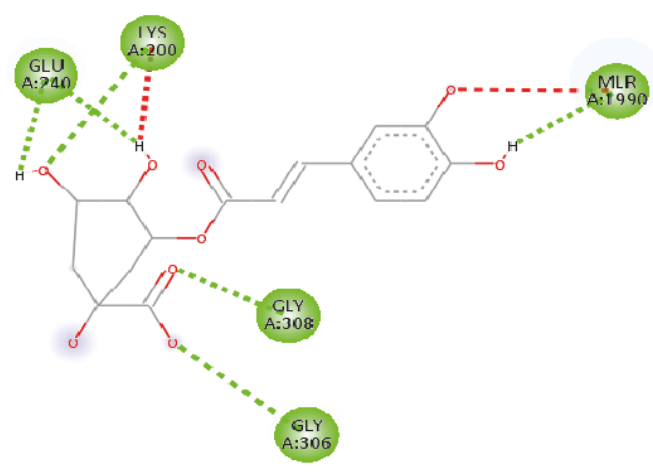

(c)

FIGURE 8: Molecular docking for chlorogenic acid with $\alpha$-amylase (a). Binding uncompetitive mode (b) and two-dimensional interaction diagram (c). Green and red dashed lines show hydrogen bonds and unfavorable donor-donor interactions, respectively. Residues involved in hydrogen bonds (green circles) are shown. 


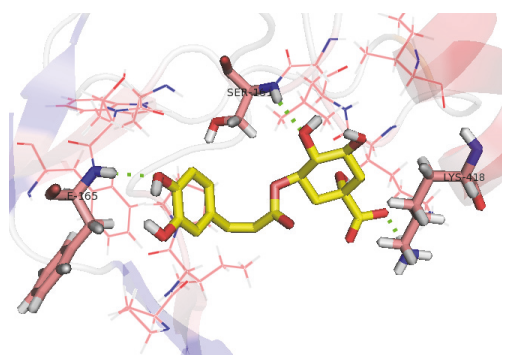

(a)

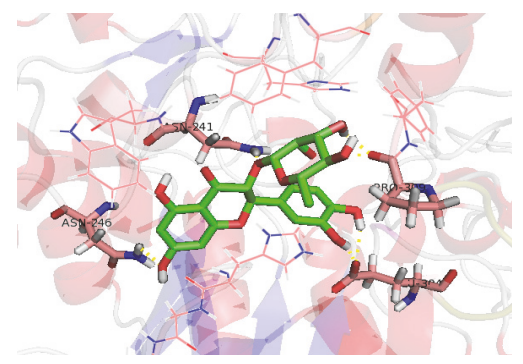

(b)

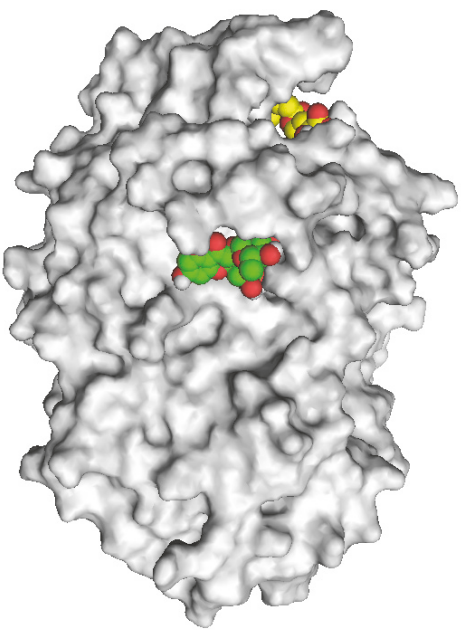

(c)

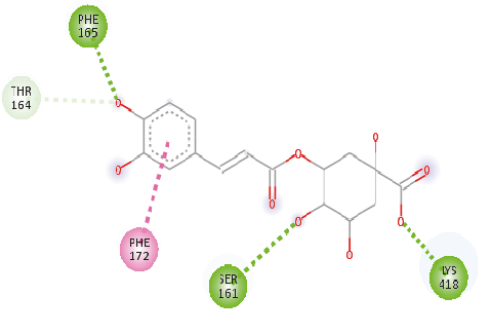

(d)

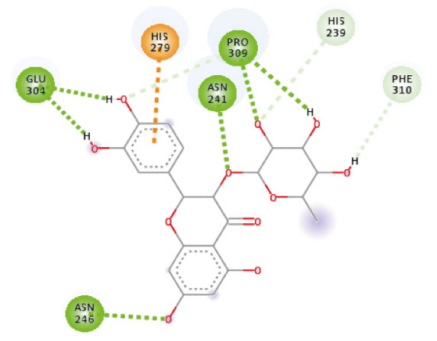

(e)

Figure 9: Molecular docking for chlorogenic acid (yellow) and astilbin (green) with $\alpha$-glucosidase (c). Docking of chlorogenic acid (a) and astilbin (b) and corresponding two-dimensional interaction diagrams (d, e). Green dashed lines show hydrogen bonds. Residues involved in hydrogen bonds (green circles), $\pi-\pi$ T-shaped (pink circles), or $\pi$-cation (orange circles) interactions are shown.

the inhibition on $\alpha$-glucosidase, compared to quercetin, astilbin formed hydrogen bonds between hydroxyl groups of rhamnosyl moiety and HIS239, PRO309, and PHE310 [49]. Flavonoids like apigenin presented noncompetitive inhibition against $\alpha$-glucosidase, its binding site is very similar to astilbin, and the interaction with residues close to active site might induce channel closure to prevent access of the substrate [23]. Previous studies have shown that the number of hydrogen bonds had no effect on binding affinity; the hydroxylation of flavonoids improved the inhibitory effects against $\alpha$-glucosidase, which might cause conformational changes in the enzyme structure. In both molecular docking analyses, hydrogen bonds had an important role in biological recognition process and implication of $\pi-\pi$ stacking interaction might be the origin of the enhanced inhibitory activities [5].

\section{Conclusions}

This is the first report on the presence of chlorogenic acid and astilbin in the roots of Smilax aristolochiifolia and on the inhibition of $\alpha$-glucosidase by astilbin. Our results indicate that these compounds exert noncompetitive inhibition through two different binding sites on $\alpha$-glucosidase. Moreover, chlorogenic acid shows an efficient in vitro uncompetitive inhibition against $\alpha$-amylase. Our results suggested that inhibition of $\alpha$-glucosidase and $\alpha$-amylase by Smilax aristolochiifolia and its compounds chlorogenic acid and astilbin could be one of the mechanisms of the hypoglycemic properties attributed to this plant. However, their antidiabetic potential need be corroborated on in vivo assays of postprandial hyperglycemia.

\section{Data Availability}

The data used to support the findings of this study are available from the corresponding author upon request.

\section{Conflicts of Interest}

The authors declare that there are no conflicts of interest regarding the publication of this paper.

\section{Acknowledgments}

This work was partially supported by FOMIT-CONACYT (Grant no. 194010) and NutriOmics Research Chair from Tecnológico de Monterrey. The authors are grateful to Dr. M. Chazaro for their assistance in the localization and characterization of S. aristolochiifolia. Viridiana Candelaria PérezNájera received a scholarship from CONACYT (no. 268829). 


\section{Supplementary Materials}

Supplementary 1. Figure S1: profile of S. aristolochiifolia root extract obtained by aqueous infusion (blue) and hydroethanolic maceration (red). HPLC UV/Vis at $280 \mathrm{~nm}$. Extraction conditions for aqueous infusion were $60^{\circ} \mathrm{C}$ under stirring for 1 hour and hydroethanolic maceration consisted in leaving the sample in ethanol: water $(1: 1 \mathrm{v} / \mathrm{v})$ at room temperature $\left(25^{\circ} \mathrm{C}\right)$ and stirring overnight; in both processes, the solid : liquid proportion of $1: 20 \mathrm{w} / \mathrm{v}$ was used.

Supplementary 2. Table S1: $k_{d}$ values of the major peaks of SAR at different concentrations in two solvents systems.

\section{References}

[1] C. D. Mathers and D. Loncar, "Projections of global mortality and burden of disease from 2002 to 2030," PLoS Medicine, vol. 3, no. 11, article e442, 2006.

[2] N. Ahmed, "Advanced glycation endproducts-role in pathology of diabetic complications," Diabetes Research and Clinical Practice, vol. 67, no. 1, pp. 3-21, 2005.

[3] R. Tundis, M. R. Loizzo, and F. Menichini, "Natural products as $\alpha$-amylase and $\alpha$-glucosidase inhibitors and their hypoglycaemic potential in the treatment of diabetes: an update," MiniReviews in Medicinal Chemistry, vol. 10, no. 4, pp. 315-331, 2010.

[4] P. M. Sales, P. M. Souza, L. A. Simeoni, P. O. Magalhães, and D. Silveira, " $\alpha$-Amylase Inhibitors: A Review of Raw Material and Isolated Compounds from Plant Source," Journal of Pharmacy \& Pharmaceutical Sciences, vol. 15, no. 1, p. 141, 2012.

[5] J. Xiao, G. Kai, K. Yamamoto, and X. Chen, "Advance in dietary polyphenols as $\alpha$-glucosidases inhibitors: a review on structureactivity relationship aspect," Critical Reviews in Food Science and Nutrition, vol. 53, no. 8, pp. 818-836, 2013.

[6] Y. Kim, J. Keogh, and P. Clifton, "Polyphenols and Glycemic Control," Nutrients, vol. 8, no. 1, p. 17, 2016.

[7] A. Satija, S. N. Bhupathiraju, E. B. Rimm et al., "Plant-Based Dietary Patterns and Incidence of Type 2 Diabetes in US Men and Women: Results from Three Prospective Cohort Studies," PLoS Medicine, vol. 13, no. 6, Article ID e1002039, 2016.

[8] H. Nyambe-Silavwe and G. Williamson, "Polyphenol- and fibre-rich dried fruits with green tea attenuate starch-derived postprandial blood glucose and insulin: A randomised, controlled, single-blind, cross-over intervention," British Journal of Nutrition, vol. 116, no. 3, pp. 443-450, 2016.

[9] R. Mata, S. Cristians, S. Escandón-Rivera, K. Juárez-Reyes, and I. Rivero-Cruz, "Mexican antidiabetic herbs: Valuable sources of inhibitors of $\alpha$-glucosidases," Journal of Natural Products, vol. 76, no. 3, pp. 468-483, 2013.

[10] Smilax aristolochiifolia Mill, http://tropicos.org/Name/18404061.

[11] A. Andrade-Cetto and M. Heinrich, "Mexican plants with hypoglycaemic effect used in the treatment of diabetes," Journal of Ethnopharmacology, vol. 99, no. 3, pp. 325-348, 2005.

[12] A. J. Alonso-Castro, F. Domínguez, J. R. Zapata-Morales, and C. Carranza-Álvarez, "Plants used in the traditional medicine of Mesoamerica (Mexico and Central America) and the Caribbean for the treatment of obesity," Journal of Ethnopharmacology, vol. 175, pp. 335-345, 2015.

[13] R. Velasco-Lezama, A. M. Torres, R. T. Aguilar et al., "Hematopoietic activity of smilax aristolochiaefolia (zarzaparrilla) in mice with aplastic anemia," Proceedings of the Western Pharmacology Society, vol. 52, pp. 83-87, 2009.
[14] C. A. B. Amaro, M. González-Cortazar, M. Herrera-Ruiz et al., "Hypoglycemic and hypotensive activity of a root extract of Smilax aristolochiifolia, standardized on N-trans-feruloyltyramine," Molecules, vol. 19, no. 8, pp. 11366-11384, 2014.

[15] H. E. Lee, J. A. Kim, and W. K. Whang, "Chemical constituents of smilax China l. stems and their inhibitory activities against glycation, aldose reductase, $\alpha$-glucosidase, and lipase," Molecules, vol. 22, no. 3, article no. 451, 2017.

[16] B. T. Zhao, D. D. Le, P. H. Nguyen et al., "PTP1B, $\alpha$-glucosidase, and DPP-IV inhibitory effects for chromene derivatives from the leaves of Smilax china L.," Chemico-Biological Interactions, vol. 253, pp. 27-37, 2016.

[17] A. Becerra-Moreno, J. Benavides, L. Cisneros-Zevallos, and D. A. Jacobo-Velázquez, "Plants as biofactories: Glyphosateinduced production of shikimic acid and phenolic antioxidants in wounded carrot tissue," Journal of Agricultural and Food Chemistry, vol. 60, no. 45, pp. 11378-11386, 2012.

[18] G. L. Miller, "Use of dinitrosalicylic acid reagent for determination of reducing sugar," Analytical Chemistry, vol. 31, no. 3, pp. 426-428, 1959.

[19] D. M. Ortíz-Martinez, C. Rivas-Morales, M. A. de la GarzaRamos, M. J. Verde-Star, M. A. Nuñez-Gonzalez, and C. LeosRivas, "Miconia sp. increases mRNA levels of PPAR gamma and inhibits alpha amylase and alpha glucosidase," Evidence-Based Complementary and Alternative Medicine, vol. 2016, Article ID 5123519, 6 pages, 2016.

[20] B. Waszkowycz, D. E. Clark, and E. Gancia, "Outstanding challenges in protein-ligand docking and structure-based virtual screening," Wiley Interdisciplinary Reviews: Computational Molecular Science, vol. 1, no. 2, pp. 229-259, 2011.

[21] M. Liu, W. Zhang, J. Wei, and X. Lin, "Synthesis and $\alpha$-glucosidase inhibitory mechanisms of bis(2,3-dibromo-4,5-dihydroxybenzyl) ether, a potential marine bromophenol $\alpha$-glucosidase inhibitor," Marine Drugs, vol. 9, no. 9, pp. 1554-1565, 2011.

[22] Y. Liu, L. Ma, W.-H. Chen, H. Park, Z. Ke, and B. Wang, "Binding mechanism and synergetic effects of xanthone derivatives as noncompetitive $\alpha$-glucosidase inhibitors: a theoretical and experimental study," The Journal of Physical Chemistry B, vol. 117, no. 43, pp. 13464-13471, 2013.

[23] L. Zeng, G. Zhang, S. Lin, and D. Gong, "Inhibitory Mechanism of Apigenin on $\alpha$-Glucosidase and Synergy Analysis of Flavonoids," Journal of Agricultural and Food Chemistry, vol. 64, no. 37, pp. 6939-6949, 2016.

[24] Q.-F. Zhang, H.-C. Nie, X.-C. Shangguang, Z.-P. Yin, G.D. Zheng, and J.-G. Chen, "Aqueous solubility and stability enhancement of astilbin through complexation with cyclodextrins," Journal of Agricultural and Food Chemistry, vol. 61, no. 1, pp. 151-156, 2013.

[25] Q.-F. Zhang, Z.-R. Zhang, and H.-Y. Cheung, "Antioxidant activity of Rhizoma Smilacis Glabrae extracts and its key constituent-astilbin," Food Chemistry, vol. 115, no. 1, pp. 297-303, 2009.

[26] C.-L. Lu, Y.-F. Zhu, M.-M. Hu et al., "Optimization of astilbin extraction from the rhizome of smilax glabra, and evaluation of its anti-inflammatory effect and probable underlying mechanism in lipopolysaccharide-induced raw264.7 macrophages," Molecules, vol. 20, no. 1, pp. 625-644, 2015.

[27] J.-H. Kim, T.-S. Park, S.-H. Yang, J.-W. Suh, and S.-M. Shim, "Microbial bioconversion and processing methods enhance the phenolic acid and flavonoids and the radical scavenging 
capacity of Smilax china L. leaf," Journal of the Science of Food and Agriculture, vol. 96, no. 3, pp. 878-885, 2016.

[28] Q. Du, L. Li, and G. Jerz, "Purification of astilbin and isoastilbin in the extract of smilax glabra rhizome by high-speed countercurrent chromatography," Journal of Chromatography A, vol. 1077, no. 1, pp. 98-101, 2005.

[29] L. Li, B. Li, H. R. Zhang et al., "Ultrafiltration LC-ESI-MSn screening of MMP-2 inhibitors from selected Chinese medicinal herbs Smilax glabra Roxb., Smilax china L. and Saposhnikovia divaricata (Turcz.) Schischk as potential functional food ingredients," Journal of Functional Foods, vol. 15, pp. 389-395, 2015.

[30] C. Ao, T. Higa, T. D. Khanh, A. Upadhyay, and S. Tawata, "Antioxidant phenolic compounds from Smilax sebeana Miq.," LWT - Food Science and Technology, vol. 44, no. 7, pp. 1681-1686, 2011.

[31] Y. Li, W. Shi, Y. Li et al., "Neuroprotective effects of chlorogenic acid against apoptosis of PC12 cells induced by methylmercury," Environmental Toxicology and Pharmacology, vol. 26, no. 1, pp. 13-21, 2008.

[32] K. Karthikesan, L. Pari, and V. P. Menon, "Antihyperlipidemic effect of chlorogenic acid and tetrahydrocurcumin in rats subjected to diabetogenic agents," Chemico-Biological Interactions, vol. 188, no. 3, pp. 643-650, 2010.

[33] A. Andrade-Cetto, J. Becerra-Jiménez, and R. CárdenasVázquez, "Alfa-glucosidase-inhibiting activity of some Mexican plants used in the treatment of type 2 diabetes," Journal of Ethnopharmacology, vol. 116, no. 1, pp. 27-32, 2008.

[34] P. Nicasio, L. Aguilar-Santamaría, E. Aranda, S. Ortiz, and M. González, "Hypoglycemic effect and chlorogenic acid content in two Cecropia species," Phytotherapy Research, vol. 19, no. 8, pp. 661-664, 2005.

[35] A. J. Alonso-Castro, A. C. Miranda-Torres, M. M. GonzálezChávez, and L. A. Salazar-Olivo, "Cecropia obtusifolia Bertol and its active compound, chlorogenic acid, stimulate 2NBDglucose uptake in both insulin-sensitive and insulin-resistant 3T3 adipocytes," Journal of Ethnopharmacology, vol. 120, no. 3, pp. 458-464, 2008.

[36] M. B. Sanchez, E. Miranda-Perez, J. C. G. Verjan, M. de los Angeles Fortis Barrera, J. Perez-Ramos, and F. J. AlarconAguilar, "Potential of the chlorogenic acid as multitarget agent: Insulin-secretagogue and PPAR $\alpha / \gamma$ dual agonist," Biomedicine \& Pharmacotherapy, vol. 94, pp. 169-175, 2017.

[37] L. Y. Zuñiga, M. C. Aceves-de la Mora, M. González-Ortiz, J. L. Ramos-Núñez, and E. Martínez-Abundis, "Effect of Chlorogenic Acid Administration on Glycemic Control, Insulin Secretion, and Insulin Sensitivity in Patients with Impaired Glucose Tolerance," Journal of Medicinal Food, 2017.

[38] V. Marques and A. Farah, "Chlorogenic acids and related compounds in medicinal plants and infusions," Food Chemistry, vol. 113, no. 4, pp. 1370-1376, 2009.

[39] S.-M. Kim, Y. F. Shang, and B.-H. Um, "Preparative separation of chlorogenic acid by centrifugal partition chromatography from highbush blueberry leaves vaccinium corymbosum L," Phytochemical Analysis, vol. 21, no. 5, pp. 457-462, 2010.

[40] J.-K. Moon, S. U. N. Hyui Yoo, and T. Shibamoto, "Role of roasting conditions in the level of chlorogenic acid content in coffee beans: correlation with coffee acidity," Journal of Agricultural and Food Chemistry, vol. 57, no. 12, pp. 5365-5369, 2009.

[41] M. T. Torres-Mancera, J. Cordova-L, G. Rodríguez-Serrano, J. Cordova-López, and G. Rodríguez-Serrano, "Enzymatic extraction of hydroxycinnamic acids from coffee pulp," Food Technol. Biotechnol, vol. 49, no. 3, pp. 369-373, 2011.
[42] Q.-F. Zhang, S.-C. Li, W.-P. Lai, and H.-Y. Cheung, “ $\beta$-Cyclodextrin facilitates simultaneous analysis of six bioactive components in Rhizoma Smilacis Glabrae by capillary zone electrophoresis," Food Chemistry, vol. 113, no. 2, pp. 684-691, 2009.

[43] H. Q. Huang, Z. H. Cheng, H. M. Shi, W. B. Xin, T. T. Y. Wang, and L. L. Yu, "Isolation and characterization of two flavonoids, engeletin and astilbin, from the leaves of Engelhardia roxburghiana and their potential anti-inflammatory properties," Journal of Agricultural and Food Chemistry, vol. 59, no. 9, pp. 4562-4569, 2011.

[44] G. Oboh, O. M. Agunloye, S. A. Adefegha, A. J. Akinyemi, and A. O. Ademiluyi, "Caffeic and chlorogenic acids inhibit key enzymes linked to type 2 diabetes (in vitro): a comparative study," Journal of Basic and Clinical Physiology and Pharmacology, vol. 26, no. 2, pp. 165-170, 2016.

[45] V. Kasabri, E. K. Al-Hallaq, Y. K. Bustanji, K. K. Abdul-Razzak, I. F. Abaza, and F. U. Afifi, "Antiobesity and antihyperglycaemic effects of adiantum capillus-veneris extracts: In vitro and in vivo evaluations," Pharmaceutical Biology, vol. 55, no. 1, pp. 164-172, 2017.

[46] Z. Karim, M. Holmes, and C. Orfila, "Inhibitory effect of chlorogenic acid on digestion of potato starch," Food Chemistry, vol. 217, pp. 498-504, 2017.

[47] C.-M. Ma, M. Hattori, M. Daneshtalab, and L. Wang, "Chlorogenic acid derivatives with alkyl chains of different lengths and orientations: Potent $\alpha$-glucosidase inhibitors," Journal of Medicinal Chemistry, vol. 51, no. 19, pp. 6188-6194, 2008.

[48] A. Ishikawa, H. Yamashita, M. Hiemori et al., "Characterization of inhibitors of postprandial hyperglycemia from the leaves of Nerium indicum," Journal of Nutritional Science and Vitaminology, vol. 53, no. 2, pp. 166-173, 2007.

[49] H. Xu, "Inhibition kinetics of flavonoids on yeast $\alpha$-glucosidase merged with docking simulations," Protein and Peptide Letters, vol. 17, no. 10, pp. 1270-1279, 2010. 


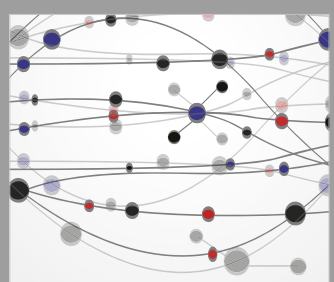

The Scientific World Journal
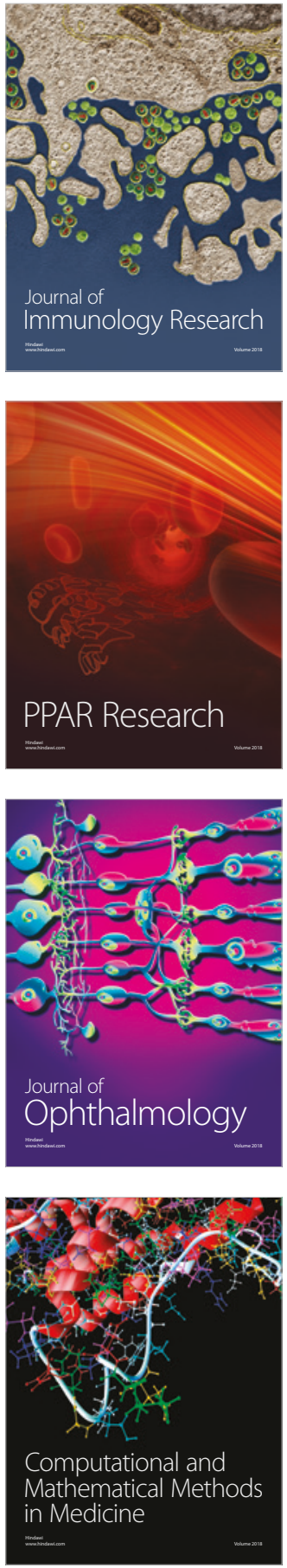

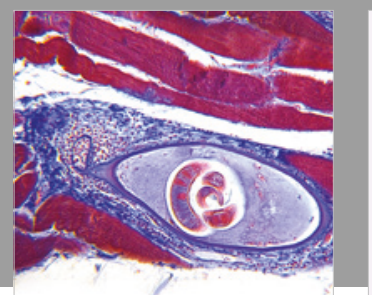

Gastroenterology Research and Practice

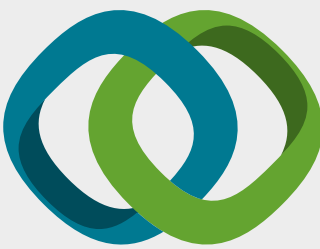

\section{Hindawi}

Submit your manuscripts at

www.hindawi.com
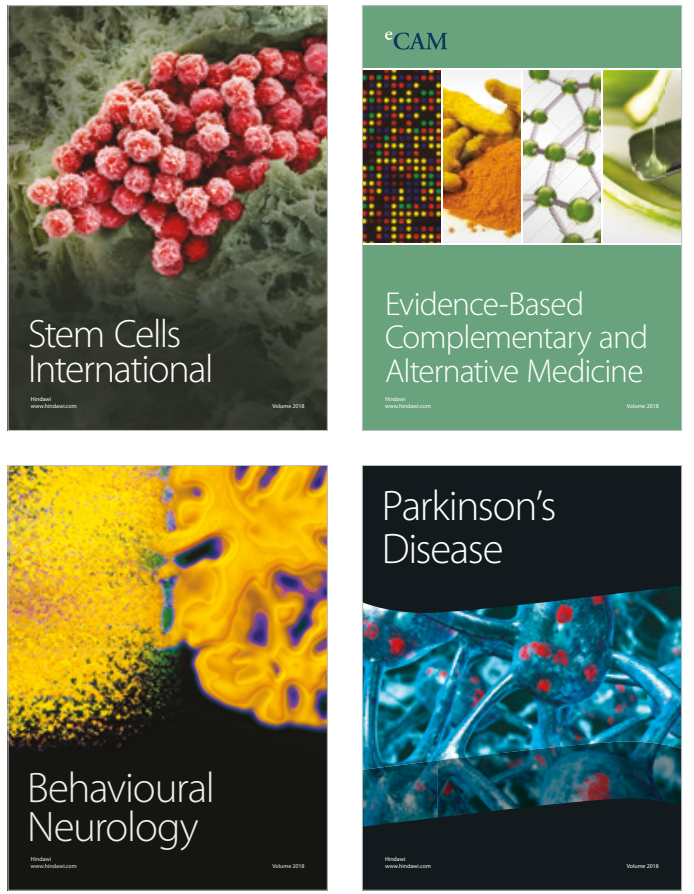

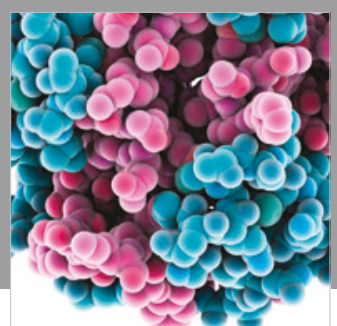

ournal of

Diabetes Research

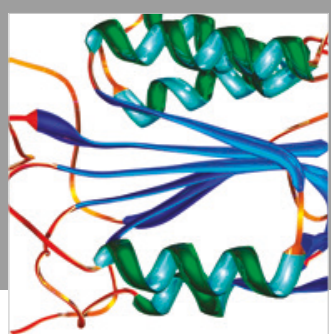

Disease Markers
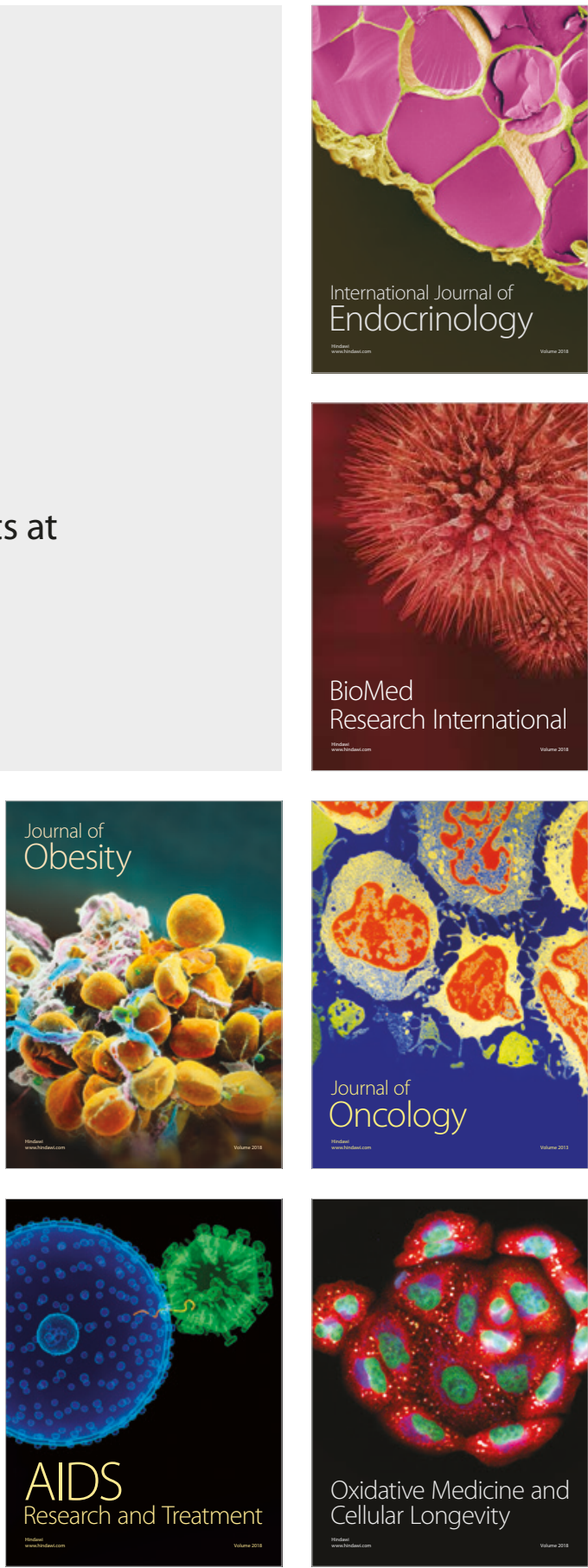